\title{
Patrimônio Agrário como Estratégia de Desenvolvimento da Comunidade Autônoma de Castilla-La Mancha (Espanha) e sua Aplicabilidade à Microrregião de Canoinhas (Santa Catarina, Brasil)
}

http://dx.doi.org/10.21527/2237-6453.2020.53.91-104

Recebido em: $25 / 5 / 2020$

Aceito em: $18 / 8 / 2020$

Alexandre Assis Tomporoski, ${ }^{1}$ Vivian Lachman, ${ }^{2}$ Julia Corrêa da Maia ${ }^{3}$

\begin{abstract}
RESUMO
O objetivo deste artigo consiste em apresentar estudos realizados no território da Comunidade Autônoma de Castilla-La Mancha (Espanha), com o intuito de investigar estratégias de desenvolvimento pautadas no conceito de patrimônio agrário e, subsequentemente, prospectar bens agrários presentes na região do Contestado (Brasil), com vistas à elaboração de estratégias congêneres de desenvolvimento regional. A abordagem metodológica considerou o exame dos planos de desenvolvimento de Castilla-La Mancha, fundamentou-se em trabalhos de campo realizados em províncias daquele território espanhol e amparou-se na revisão de literatura sobre a categoria conceitual de patrimônio agrário. Conclui-se que a busca por estratégias de desenvolvimento pode se pautar em ações análogas realizadas em outros territórios e que sua efetivação exigirá a mobilização dos atores sociais e políticos da microrregião de Canoinhas.
\end{abstract}

Palavras-chave: Patrimônio agrário. Comunidade Autônoma de Castilla-La Mancha. Microrregião de Canoinhas. Desenvolvimento regional.

AGRARIAN HERITAGE AS A DEVELOPMENT STRATEGY FOR THE AUTONOMOUS COMMUNITY OF CASTILLA-LA

MANCHA (SPAIN) AND ITS APPLICABILITY TO THE MICROREGION OF CANOINHAS (SANTA CATARINA, BRAZIL)

\section{ABSTRACT}

The objective of this article is to present studies carried out in the territory of the Autonomous Community of Castilla-La Mancha (Spain), in order to investigate strategies of development based on the concept of agrarian heritage, and subsequently consider the agrarian assets of the region of Contestado (Brazil), with a view to the establishment of similar strategies of regional development. The methodological approach considered the examination of the plans for the development of Castilla-La Mancha, based on fieldwork carried out in the provinces of that Spanish territory and supported in the review of literature on the conceptual category of agrarian heritage. It is concluded that the search for strategies of regional development can be based on similar actions carried out in other territories and that their implementation will require the mobilization of the social and political agents of the micro-region of Canoinhas.

Keywords: Agrarian heritage. Autonomous community of Castilla-La Mancha. Canoinhas Micro Region. Regional development.

\footnotetext{
${ }^{1}$ Doutor em História pela Universidade Federal de Santa Catarina (UFSC). Professor do Programa de Mestrado em Desenvolvimento Regional da Universidade do Contestado (UnC). http://lattes.cnpq.br/5928237651810241. https://orcid.org/0000-0002-3042-7844. alexandre@unc.br

${ }^{2}$ Especialista em Educação pela Universidade do Contestado (UnC). Diretora Pedagógica da Secretaria de Educação do município de Canoinhas/SC. http://lattes.cnpq.br/8074741298572682. https://orcid.org/0000-0002-9252-0788. vivianlachman.educ@gmail.com

${ }^{3}$ Graduanda em História pela Universidade do Estado de Santa Catarina (Udesc). http://lattes.cnpq.br/8074741298582861. https://orcid.org/ 0000-0002-1451-0584. juliamaia04@outlook.com
} 
O processo histórico de formação influencia sobremaneira o desenvolvimento de regiões, territórios ou países. Nesse contexto, insere-se a microrregião de Canoinhas, que compõe o território do Contestado, o qual se estende pelas regiões norte e centro-oeste do Estado de Santa Catarina. ${ }^{4}$

Em consequência de atividades historicamente relacionadas ao extrativismo de produção e à concentração fundiária, hodiernamente a microrregião de Canoinhas, comparativamente as 20 microrregiões que constituem o Estado de Santa Catarina, detém o terceiro pior Índice de Desenvolvimento Humano Municipal (IDH-M). Diante dessa conjuntura, concebem-se legítimas as propostas que visam a proporcionar estratégias alternativas de desenvolvimento.

É oportuno especificar a noção de desenvolvimento aqui adotada, que segue a orientação conceitual de Dallabrida (2015):

O desenvolvimento territorial é entendido como um processo de mudança continuada, situado histórica e territorialmente, mas integrado em dinâmicas intraterritoriais, supraterritoriais e globais, sustentado na potenciação dos recursos e ativos (materiais e imateriais, genéricos e específicos) existentes no local, com vistas à dinamização socioeconômica e à melhoria da qualidade de vida da sua população (p. 325).

A busca por estratégias alternativas de desenvolvimento perpassa pela análise das potencialidades de um determinado território. Além dos elementos endógenos - considerados aqueles recursos específicos - requer a participação ativa dos atores locais na fomentação do almejado processo de desenvolvimento, por meio da utilização dos elementos patrimoniais existentes no território que caracterizam sua identidade territorial (PLAZA; CAÑIZARES; RUIZ PULPÓN, 2017, p. 17).

Nos últimos anos, ampliou-se o debate acerca dos processos de patrimonialização, que permitem identificar, reconhecer, valorizar, preservar e difundir certos bens patrimoniais, e, em decorrência dessa abordagem, novas categorias e novos tipos de patrimônio vêm sendo criados. Neste artigo, pretende-se analisar o patrimônio agrário e suas potencialidades mediante exame de sua introdução na Comunidade Autônoma de Castilla-La Mancha, Espanha, visando à sua aplicação à microrregião de Canoinhas, tendo em vista que seu arcabouço teórico-metodológico se harmoniza com as características de ambos os territórios: valorização da atividade agrária e dos indivíduos envolvidos nesta atividade, com especial atenção aos elos mais frágeis do segmento: as práticas tradicionais e ambientalmente sustentáveis e seus executores - camponeses, criadores e pequenos proprietários - por intermédio de produção em base familiar. Em suma, o patrimônio agrário atende às demandas por desenvolvimento, pois incorpora uma finalidade tutelar distinta que consiste no aproveitamento produtivo ou acolhimento do patrimônio como fator de desenvolvimento. "Isto permite vincular o patrimônio a estratégias de desenvolvimento ou a atividades produtivas, especialmente no âmbito local" (RUIZ; YANEZ, 2015, p. 57).

\footnotetext{
${ }^{4}$ Versões preliminares do presente texto foram apresentadas em dois eventos: V Seminário Internacional de Integração e Desenvolvimento Regional, realizado na Unioeste, em Toledo (PR), no ano de 2018, e International Academic Conference. International Institute of Social and Economic Sciences, em Paris, França, no ano de 2019.
} 
Embora o propósito deste artigo consista em apresentar um estudo acerca da categoria conceitual de patrimônio agrário, instituída na Comunidade Autônoma de La Mancha (Espanha), com vistas à sua aplicabilidade à microrregião de Canoinhas (Brasil), convém descrever, inicialmente, os processos históricos concernentes à formação dos territórios sob análise. Subsequentemente, apresentar-se-ão os referenciais teóricos pertinentes à categoria conceitual de patrimônio agrário, os procedimentos metodológicos utilizados e os resultados e discussões atinentes à identificação e reconhecimento do patrimônio agrário na Espanha e, analogamente, as possibilidades latentes presentes na microrregião de Canoinhas (Brasil).

\section{O PROCESSO HISTÓRICO DE FORMAÇÃO DA MICRORREGIÃO DE CANOINHAS}

O território do Contestado, no qual se insere a microrregião de Canoinhas, em seus primórdios, foi ocupado predominantemente por populações indígenas do grupo Xokleng, que não praticavam a agricultura, apenas a caça e a coleta como meio de sobrevivência. A partir das primeiras décadas do século 18, ocorreu o início da ocupação não indígena daquele território. Esse processo intensificou-se com a abertura do Caminho de Tropas.

A partir do ano de 1728, um conjunto de estradas que conectava São Paulo ao Rio Grande do Sul - que entrecortava a microrregião de Canoinhas - foi inaugurado. O Caminho de Tropas, como ficou conhecido, permaneceu ativo por quase 200 anos, o que favoreceu o processo de ocupação e colonização da Região Sul do Brasil.

Durante as primeiras décadas do século 19, em decorrência do Caminho de Tropas e da ampliação do comércio de erva mate, as primeiras levas de imigrantes foram assentadas na microrregião de Canoinhas. No ano de 1829, ocorreu a instalação de uma colônia de imigrantes em Rio Negro (atual município de Mafra).

Dentre as características peculiares da microrregião de Canoinhas, sobressaem as disputas fundiárias e os conflitos sociais relacionados à posse e uso da terra. No início do século 20, aquele território transformou-se no palco da Guerra do Contestado (1912-1916), um dos maiores movimentos sociais da história brasileira. Aquele conflito suscitou a resistência da população camponesa à destruição do seu modo de vida e à destinação de suas terras para companhias norte-americanas do setor ferroviário e madeireiro, além de grandes proprietários rurais. No auge dos combates, a população local chegou a enfrentar, à época, mais da metade do efetivo de soldados do exército brasileiro, cerca de 7 mil homens, além das polícias locais. A repressão estatal intensificou-se com a contratação, pelos latifundiários da região, de um contingente superior a mil homens armados. Ao término do conflito, estima-se que tenham sucumbido dezenas de milhares de pessoas.

$\mathrm{Na}$ atualidade, a microrregião de Canoinhas é constituída por 12 municípios localizados no planalto norte de Santa Catarina, Região Sul do Brasil: Bela Vista do Toldo, Canoinhas, Irineópolis, Itaiópolis, Mafra, Major Vieira, Monte Castelo, Papanduva, Porto União, Santa Terezinha, Timbó Grande e Três Barras. Esse conjunto de municípios ocupa uma área total de $9.411,12 \mathrm{~km}^{2}$, e acolhe uma população de 243.739 habitantes, dos quais aproximadamente $82 \mathrm{mil}$ (cerca de $1 / 3$ do total) vivem no meio rural, à medida que cerca de 162 mil (em torno de 2/3 do total) residem em áreas urbanas (IBGE, 2014). 
É razoável delimitar três fatores vigentes na microrregião de Canoinhas que geram entraves à execução de estratégias de desenvolvimento territorial: (i) em decorrência do trauma associado ao conflito social e ao genocídio praticado contra os caboclos, durante a Guerra do Contestado, a população que reside naquele território imbuiu-se de sentimentos de vergonha, que impuseram o silenciamento sobre o movimento e a luta dos camponeses; (ii) a expansão fundiária, outrora já vivenciada, que promove a concentração da propriedade da terra, sob controle de latifundiários e de empresas multinacionais; e (iii) a perpetuação de um modelo econômico que privilegia o extrativismo de base silvícola destinado à produção de papel e celulose.

\section{O PROCESSO HISTÓRICO DE FORMAÇÃO DA COMUNIDADE AUTÔNOMA DE CASTILLA-LA MANCHA}

A Comunidade Autônoma de Castilla-La Mancha, que integra o Reino da Espanha, é constituída por cinco províncias: Albacete, Ciudad Real, Cuenca, Guadalajara e Toledo, e ocupa uma área de $79.462 \mathrm{~km}^{2}$ (INE, 2016), o que corresponde a 4,39\% da área territorial da Espanha, acolhendo uma população de 2.041 .631 habitantes, o que representa $15,70 \%$ da população espanhola.

A história de ocupação humana, no território onde localiza-se a Comunidade Autônoma de Castilla-La Mancha, remonta a milhares de anos, à época do período Paleolítico, ou seja, anterior a 10.000 anos a.C. Ao longo dos séculos, o território foi habitado por populações autóctones, celtas, ibérios, romanos, muçulmanos, etc., que contribuíram para a formação de sua história, técnicas e produção agrária (SÁEZ et al., 2014, p. 393).

Na contemporaneidade, especialmente no decorrer do século 20, eventos que determinaram os rumos da sociedade espanhola também reverberaram sobre aquele território. A Guerra Civil (1936-1939) e a instauração de uma ditadura que se estendeu por quase quatro décadas, subjugaram a Espanha. Aquele período caracterizou-se pela repressão a direitos fundamentais e supressão de liberdades individuais, além de um incisivo processo de centralização, que influenciou, inclusive, o ordenamento territorial. O processo de transição democrática, desencadeado no final da década de 70 e início dos anos 1980, pôs fim ao caráter centralizador do período anterior, desenvolvendo-se um projeto de descentralização autonômica e territorial (LÓPEZ, 2007).

Naquele contexto, em decorrência do processo de transição democrática, reorganização estatal e descentralização territorial, ocorreu o advento da "Espanha regional" ou "Estado das Autonomias". No ano de 1982 foi instituída a Comunidade Autônoma de Castilla-La Mancha.

Conquanto sua formação política e administrativa relativamente recente, as províncias que constituem a Comunidade Autônoma de Castilla-La Mancha possuem uma história milenar, fato que suscitou dificuldades de integração em razão da ausência de uma consciência regional, exigindo a consubstanciação de uma identidade de caráter regionalista.

O "novo" território de Castilla-La Mancha consistia em "Um espaço de discutível passado em comum, com uma conformação territorial que jamais havia existido (...) despossuído de referentes históricos sobre os quais cimentar-se" (LÓPEZ, 2007, p. 390). 
Diante daquela realidade, a construção de uma nova identidade territorial representou intento peremptório à nova comunidade autônoma. A nova formação territorial, caracterizada pela originalidade e singularidade, exigia a elaboração de novos elos identitários. A consecução dessa árdua tarefa foi favorecida por um fator que contribuiu decisivamente: a riqueza patrimonial castellano-manchega.

A riqueza patrimonial de Castilla-La Mancha decorre de sua história milenar, caracterizada pela diversidade de povos e culturas que habitaram o território. Essa asseveração é corroborada pelo fato de a Unesco ter reconhecido, como Patrimônio da Humanidade, quatro sítios localizados naquele território: a Cidade Histórica de Toledo, a Cidade História de Cuenca, o Parque Mineiro de Almadén e as Pinturas Rupestres. Além dessas quatro referências notórias, é possível citar parques arqueológicos, castelos, museus e numerosos remanescentes do período romano.

Desde a última década do século 20, esse amplo conjunto patrimonial territorial vem sendo progressivamente valorizado, incrementando significativamente a atividade turística. Convém salientar que acentuada parcela dos turistas que visita Castilla-La Mancha provém de regiões vizinhas, especialmente da capital, Madrid. A estrutura turística desenvolve-se em decorrência do aumento da demanda, o que permite inferir uma tendência de expressivo crescimento, haja vista o potencial territorial de La Mancha. Neste âmbito, o patrimônio territorial representa um recurso cultural e econômico (PILLET, 2011, p. 727), fato que proporciona ao setor turístico a capacidade de contribuir como estratégia de desenvolvimento territorial.

\section{O CONCEITO DE PATRIMÔNIO AGRÁRIO}

A categoria conceitual de patrimônio agrário foi essencialmente desenvolvida por um grupo de pesquisadores da Universidade Internacional de Andaluzia, em Granada, Espanha, ampliando a capacidade analítica das ferramentas acadêmicas disponíveis, e foi consolidada na Carta de Baeza (RUIZ, 2013), segundo a qual: “O Patrimônio Agrário está conformado pelo conjunto de bens naturais e culturais, materiais e imateriais, gerados ou aproveitados pela atividade agrária ao longo da história" (RUIZ; YANEZ, 2015, p. 452).

A definição de patrimônio agrário incorpora um amplo conjunto de bens:

(...) bienes muebles (utensilios, aperos o herramientas utilizados para la labranza, transporte, almacenaje y manufactura de los cultivos y el ganado, documentos y objetos bibliográficos, etc.), bienes inmuebles singulares (elementos constructivos considerados singularmente: cortijos, huertas, centros de transformación agraria, graneros, cercados, eras, etc.), bienes inmuebles de conjunto o lineales (paisajes, asentamientos rurales, sistemas de riego, agroecosistemas singulares, vías pecuarias, caminos, etc.), patrimonio inmaterial (linguística, creencias, rituales y actos festivos, conocimientos, gastronomía y cultura culinaria, técnicas artesanales, tesoros vivos, etc.) y patrimonio natural y genético (variedades locales de cultivos, razas autóctonas de animales, semillas, suelos, vegetación y animales silvestres asociados, etc.) (RUIZ, 2013).

Não obstante a Carta de Baeza se constituir em documento normativo que permite a difusão internacional do conceito de patrimônio agrário, viabilizando sua aplicação a bens agrários situados em quaisquer países do mundo, seja na comunidade autônoma de Castilla-La Mancha, na Espanha, ou na microrregião de Canoinhas, no Brasil, o 
conjunto de investigações que estabeleceu os parâmetros considerados pela Carta, denominado de "Projeto PAGO: O patrimônio agrário: a construção cultural do território através da atividade agrária", fora publicado em obra sob mesmo título (2015). Ao longo do texto, os autores explicam o objetivo do conceito de patrimônio agrário, que consiste em proporcionar uma visão integrada, contemplando bens dotados de valor agrário em seus aspectos inter-relacionais, conjuntamente, evitando-se o reconhecimento fragmentado e descontextualizado dos bens agrários. Os processos de singularização também podem suscitar empecilhos, pois, ao se privilegiar determinados aspectos de um produto em detrimento de outros, impõe-se um papel secundário à atividade agrária, subordinando-a e obscurecendo a importância do agrário (RUIZ; YANEZ, 2015, p. 29). Tal é o caso, por exemplo, do vinho, pois, ao fixar o interesse no produto em si, desconsidera-se seu cultivo e os processos que o envolvem.

A Carta de Baeza (RUIZ, 2013) enfatiza valores agroecológicos e ambientais em sua contínua disputa - que ocorre em âmbito global e se manifesta em âmbito local - contra as práticas agrícolas predatórias, disseminadas pelo agronegócio, que "tantos efeitos destrutivos está tendo sobre o Meio Ambiente, sobre a biodiversidade cultivada, sobre a alimentação humana ou sobre os direitos dos agricultores e dos povos indígenas" (RUIZ; YANEZ, 2015, p. 43).

A identificação, reconhecimento e valorização dos bens patrimoniais agrários, processo comumente denominado por "patrimonialização", quando efetivado, poderá gerar benefícios a um determinado território. Tal processo de patrimonialização tende a incrementar medidas protetivas, além de medidas de fomento - por meio do aporte de recursos governamentais ou mesmo externos, a título de exemplo, dos países da União Europeia - e difusão dos referidos bens, inclusive do próprio território, propiciando a obtenção de uma perspectiva abrangente e integrada dos bens agrários, o que possibilita a formação de uma percepção ampla acerca das características e do potencial agrário de determinada sociedade. Este fato, que excede o potencial econômico, promove o reconhecimento e o fortalecimento da identidade territorial, seja pelas pessoas e instituições exteriores ao território, seja pelos próprios indivíduos que ali residem. No caso de trabalhadores envolvidos em atividades agrárias, tende a elevar a autoestima e o sentimento de pertencimento a um determinado lugar e sua respectiva identidade. Em relação aos demais indivíduos, não diretamente envolvidos com a atividade agrária caso da população urbana do território, onde tais bens foram identificados - suscita uma valorização que desencadeia a conscientização e o respeito tanto pela atividade agrária quanto por aqueles que a realizam. Do mesmo modo, o reconhecimento e o fortalecimento da identidade territorial também pode promover a elevação dos níveis de capital social em determinada sociedade, condição sine qua non aos processos de desenvolvimento endógeno.

Dentre as exigências que incidem sobre os bens passíveis de patrimonialização, destaca-se a necessidade de existência de uma perspectiva histórica, ou seja, práticas agrárias e bens decorrentes das mesmas precisam possuir valor cultural, tendo percorrido um processo de (res)significação cultural, algo que apenas se manifesta com a passagem do tempo. Isto exclui bens do tempo presente e práticas recentes inseridas em determinado cenário produtivo. 
Os bens que admitem patrimonialização, por intermédio do conceito de patrimônio agrário - conforme exposto anteriormente -, portanto, precisam possuir vínculos com a função agrária executada diretamente pelo agricultor, além de apresentar um caráter histórico. Naqueles casos em que o valor agrário sofreu significativa depreciação, tal valor será reconhecido a partir de seus atributos históricos concernentes à história da agricultura (RUIZ; YANEZ, 2015, p. 37). Por outro lado, aqueles bens utilizados em práticas agrárias vigentes e produtivas também poderão obter proteção. Esta característica do conceito possibilita a proteção de agrossistemas vivos, suprimindo a ideia de que a patrimonialização exige um processo de fossilização do bem protegido. Neste caso, os agricultores, adicionalmente, mantêm os processos produtivos e a consequente valoração agrária dos bens.

O processo de patrimonialização de quaisquer tipos de bens tende a atrair a atenção da sociedade no entorno. As propostas de patrimonialização movimentam os atores sociais, políticos e econômicos de determinado território, e promovem a ampliação dos debates e estudos acerca dos bens em consideração. No caso específico do patrimônio agrário, o processo de patrimonialização permite a identificação, reconhecimento e valorização dos bens patrimoniais agrários, que se encontram integrados a outros elementos presentes no território. Assim, a curto prazo, tende a ocorrer uma conscientização da sociedade sobre a importância daquele bem, assim como a valorização da atividade agrária em geral - normalmente percebida como de baixo status socioeconômico - e, em última instância, o reconhecimento e a valorização das pessoas, mulheres e homens, que se dedicam ao trabalho no campo. O movimento inicial, executado a partir da proposta de aplicação do patrimônio agrário, portanto, contribui para atender a um dos aspectos elencados no conceito, necessário para justificar sua existência e reconhecimento: que a sociedade tome consciência da importância do bem a ser preservado. Esse fato também propiciará, a uma parcela significativa da população envolvida no debate, sua identificação com determinado bem agrário (seja material ou imaterial), permitindo a autoidentificação com aquele bem, com o território, com o grupo social diretamente responsável pelo bem e, no sentido amplo, com a história daquele território. Tem, então, condições de promover a potencialização dos elementos que compõem a identidade cultural daquele território, propiciando a ampliação do capital social e fomentando os processos de desenvolvimento.

Em decorrência da identificação, reconhecimento, valorização e conservação de um determinado bem, propende o aporte de algum tipo de recurso, inclusive financeiro, e, ao final, este bem - e o território em que está inserido - obtém visibilidade por meio da sua divulgação. Esse processo apresenta potencial para embasar outras alternativas, inclusive de ordem econômica, tal qual o turismo. Cabe ressaltar que o objetivo do patrimônio agrário não se confunde com a geração de bem ou serviço para atender a demanda de consumidores. Seu objetivo consiste na proteção e reconhecimento dos bens utilizados pela atividade agrária, com resultados não mercadológicos, que podem gerar benefícios coletivos significativos.

Assim sendo, pressupostamente o patrimônio agrário pode proporcionar uma série de benefícios a um determinado território, inclusive converter-se em recurso pragmático de desenvolvimento, haja vista possibilitar a organização social e comunitária no 
entorno dos elementos patrimoniais agrários capazes de serem valorizados e protegidos, inclusive de forma institucional, a exemplo da Unesco, fomentando estratégias que visem à melhoria da qualidade de vida da população que ali reside.

\section{PROCEDIMENTOS METODOLÓGICOS}

A metodologia utilizada considerou o exame dos planos de desenvolvimento da Comunidade Autônoma de Castilla-La Mancha, fundamentou-se em trabalhos de campo realizados em várias províncias daquele território espanhol e amparou-se na revisão da literatura disponível acerca do conceito de patrimônio agrário. Por conseguinte, avaliou-se a aplicação desta categoria conceitual a bens agrários identificados na microrregião de Canoinhas (Brasil), com vistas à sua possível utilização em estratégias de desenvolvimento congêneres.

No Reino da Espanha, inicialmente analisou-se o Plano Estratégico de Turismo (2015-2019) de Castilha-La Mancha, intitulado “Missão, Visão e Objetivos Estratégicos. Desenvolvimento de Planos e Linhas de Atuação". Além do plano em si, foi consultada literatura especializada e dados disponibilizados pelo Instituto Nacional de Estadistica, da Espanha. Paralelamente, realizou-se uma ampla revisão da literatura disponível (quase que exclusivamente produzida na Espanha) sobre o conceito de patrimônio agrário.

Posteriormente, visando a identificar as características, limites e possibilidades do processo de construção de identidade territorial a partir dos signos distintivos do território de La Mancha, foram avaliadas, por meio de trabalhos de campo, as características presentes naquele território espanhol, objetivando, dentre outros, identificar os monumentos que amparam o turismo artístico, avaliar as condições naturais que fomentam o turismo rural e de aventura, analisar as potencialidades que favorecem o turismo histórico e reconhecer as tradições, culturas e legados intrínsecos ao território de Castilha-La Mancha, capazes de viabilizar estratégias indutoras de desenvolvimento.

$\mathrm{Na}$ etapa seguinte, de posse do aparato teórico-metodológico relacionado ao conceito de patrimônio agrário e dos dados coletados, iniciou-se o processo de análise, de caráter qualitativo e exploratório, quanto às possíveis aplicações do conceito de patrimônio agrário à microrregião de Canoinhas (Brasil).

\section{RESULTADOS E DISCUSSÕES}

A adoção do conceito de patrimônio agrário, além de valorizar práticas agrárias tradicionais, pode fomentar estratégias alternativas de desenvolvimento.

Nesse contexto, convém apresentar os principais aspectos relacionados ao patrimônio agrário verificados na Comunidade Autônoma de Castilla-La Mancha (Espanha) e, posteriormente, aduzir elementos congêneres existentes na microrregião de Canoinhas (Brasil).

\section{O Patrimônio Agrário da Comunidade Autônoma de Castilha-La Mancha}

Este artigo considera, preponderantemente, os seguintes elementos presentes no território de Castilla-La Mancha relacionados ao patrimônio agrário: (i) as atividades de vitivinicultura e (ii) a Rota de Dom Quixote. 
A valorização do patrimônio vitivinícola, em seu aspecto de produto turístico cultural e gastronômico, configura uma estratégia inovadora de desenvolvimento territorial. Sob esse enfoque, é razoável considerar que a Carta de Baeza representa a consolidação de uma metodologia voltada à ordenação e classificação de quaisquer atividades produtivas agrárias, inclusive os vinhedos (PLAZA; CAÑIZARES; RUIZ PULPÓN, 2017, p. 7).

Convém salientar que o conceito de patrimônio agrário admite sua aplicabilidade a bens vinícolas, pois a categoria incorpora qualquer atividade, objeto, ou mesmo produto, que seja realizado, criado ou produzido "pelo agricultor como parte do processo produtivo agrário" (RUIZ; YANEZ, 2015, p. 30). Isto sugere que a atividade de cultivo da uva - conquanto o aumento progressivo da mecanização e a introdução sistemática do cultivo em espaldeira (que incrementa o uso da mecanização) - é passível de identificação e reconhecimento enquanto bem agrário.

No território de Castilla-La Mancha o cultivo de uvas consiste em atividade altamente relevante, ocupando uma área de aproximadamente 80 mil quilômetros quadrados - maior área do continente europeu destinada à produção de uvas, o que representa quase metade de todo o cultivo espanhol $(46,1 \%)$, cerca de $13 \%$ de todo o cultivo europeu e em torno de $6 \%$ da área cultivada em âmbito global (PLAZA; CAÑIZARES; RUIZ PULPÓN, 2017, p. 4). A atividade vinícola vem recebendo importantes esforços de patrimonialização, objetivando incorporá-la ao circuito turístico.

Os processos de patrimonialização da vitivinicultura relacionam-se, de maneira geral, com a obtenção dos "selos de qualidade", que, em última instância, permitem viabilizar a agregação de valor a um determinado produto - no caso do vinho - em conformidade com as exigências e demandas dos mercados globais. O processo de homogeneização, tanto cultural quanto de produção, entretanto, também subjaz ameaças, tendo em vista sua influência para a concentração das atividades agrárias. No caso de Castilla-La Mancha, os vinhedos geram demanda por extensas áreas territoriais, implicando acentuada redução da população economicamente ativa que trabalha na agricultura, condição que poderá ser agravada, por exemplo, com a adoção de novas técnicas a exemplo da uva em espaldeira - e pelo avanço da mecanização no processo de cultivo da uva.

La morfología de un viñedo en espaldera es totalmente distinta al de uno en vaso. A la mayor distancia entre las hileras, se le añade la utilización de postes, de alambres y de conducciones de riego por goteo que condicionan la disposición emparrada de los sarmientos, facilitando las labores de mecanización (RUIZ PULPÓN, 2013, p. 256).

Além de sua patrimonialização, a valorização do produtor e das práticas tradicionais ainda em uso, ligadas ao processo de cultivo da vendimia - colheita manual -, possibilita privilegiar a sustentabilidade, pois os vinhedos cultivados diretamente sobre 0 solo, sem o estaqueamento, mitigam o consumo d'água, contribuindo para o equilíbrio ambiental. Após o produtor realizar a vendimia e destinar sua produção à vinícola, encerra-se a prática agrária do cultivo da uva e se inicia o processo agroalimentário de produção do vinho, o qual, por sua vez, não integra o rol de bens passíveis de patrimonialização, de acordo com o conceito de patrimônio agrário. 
Acerca do patrimônio imaterial de Castilla-La Mancha, a significativa diversidade de bens percebidos como patrimonializáveis, exigiram novas formas de organização e gestão, implicando em discrepâncias interpretativas acerca dos bens culturais considerados "reais" e aqueles "criados artificialmente" (RUIZ; YANEZ, 2015, p. 55). Neste segundo grupo admite-se incluir, por exemplo, as rotas de Quixote.

A Rota de Dom Quixote teve início com a celebração, no ano de 2005, dos 400 anos de publicação da obra de Miguel de Cervantes. A rota atravessa $16 \%$ dos municípios da região de La Mancha, totalizando 2.500 quilômetros. Apesar dos esforços, ainda não obteve êxito no mercado turístico, fato que influenciou o Plano Estratégico de Turismo (2010-2014), o qual propôs o desenvolvimento de "Cenários de Quixote", consistindo em "painéis visuais que criem vínculos tangíveis com episódios/cenas da obra" (PILLET, 2011, p. 735).

O Plano Estratégico de Turismo (2015-2019) considera a condição de Castilla-La Mancha destino turístico, capaz de competir em âmbitos nacional e internacional, utilizando estratégias de marketing como ferramenta para elevar a presença, permanência e gastos dos turistas.

Indubitavelmente, aqueles territórios que buscam alternativas de desenvolvimento econômico, dentre as quais a atividade turística, adquirem vantagem estratégica. A ampliação do turismo de massa, em decorrência da difusão do acesso à informação, por intermédio da mídia em geral, especialmente via internet, aliada à ampliação do alcance e minoração de custos de sistemas de transporte, tende a favorecer a expansão do setor. Neste contexto, a trajetória de Dom Quixote obtém enorme potencial, transformando-se em produto cultural que agrega altíssimo valor.

Além do aspecto mercadológico, outro fator adquire relevância: a elaboração de uma identidade territorial - uma carência de Castilla-La Mancha em decorrência de seu recente processo de formação política e administrativa - embasada na figura de Dom Quixote e nas referências territoriais presentes na narrativa da magistral obra de Cervantes. Não há como permanecer alheio à influência de uma história com mais de quatro séculos, que mantém uma relação bastante íntima com o território que lhe serviu de cenário. A valorização desse bem cultural permite promover o fortalecimento e a consolidação da identidade territorial de Castilla-La Mancha. Certamente este processo beneficia-se do suporte disponibilizado pelos poderes públicos, com exemplos que vão do mais trivial até o mais imponente e sofisticado.

No caso específico da Rota, cabe realçar ações já desenvolvidas para sua conservação e revitalização. Um exemplo consiste nos moinhos localizados nos Campos de Criptana, em Alcázar de San Juan, província de Ciudad Real. Além de representarem uma importante categoria patrimonial, do ponto de vista territorial, uma parcela deles, na condição de componente da Rota do Quixote, transformou-se em centro de interpretação territorial, o que agregou enorme valor científico e pedagógico ao roteiro.

\section{O Patrimônio Agrário da Microrregião de Canoinhas}

Com o intuito de propor aplicações do conceito de patrimônio agrário a elementos existentes na microrregião de Canoinhas, este estudo identificou, a partir da análise da literatua disponível sobre a microrregião em tela, um conjunto de bens agrários, 
materiais e imateriais que admitem patrimonialização, selecionando os seguintes representantes: (i) a produção da erva-mate (patrimônio agrário material) e (ii) o pixirum (patrimônio agrário imaterial).

Antecedendo a discussão sobre os aspectos inerentes aos bens agrários selecionados, é conveniente discorrer sobre os demais elementos que poderão compor o conjunto patrimonial agrário da região sob enfoque.

No que concerne ao patrimônio agrário material, há a presença de um significativo patrimônio natural constituído por um ecossistema de relevante valor ambiental - a Floresta Ombrófila Mista (FOM) -, ecossistema oriundo de uma formação florestal integrante do bioma Mata Atlântica, também conhecida como mata de pinhais ou floresta de araucária. Em relação ao conjunto patrimonial imaterial diretamente ligado à atividade agrária, que agrega relevante valor sociocultural, podem-se citar os seguintes elementos: (a) prática religiosa denominada naquela região de fandango ou dança de São Gonçalo; (b) a tradição de São João Maria, santo popular que foi, na realidade, um peregrino italiano que atravessou aquela região durante o século 19; (c) patrimônio gastronômico, com variedades de pratos à base de pinhão, o fruto do pinheiro araucária, espécie de destaque naquele território, além de pratos que variam da comida cabocla tradicional àqueles de origem alemã, como o Einsbein (joelho de porco) e a cuca, e uma torta produzida com massa de trigo e frutas locais, algo desconhecido na culinária alemã.

Acerca da erva-mate, representante do patrimônio agrário material, trata-se de uma planta cujas folhas trituradas são consumidas sorvidas em água (quente ou fria), e seu uso remonta aos indígenas nativos da região. O consumo do chimarrão (nome da bebida elaborada com a erva-mate) difundiu-se por todo o sul do continente americano, com incidência da planta em uma área de 540 mil hectares, dos quais 450 mil encontram-se no Brasil, abrangendo a bacia do Prata (GERHARDT, 2013).

A erva-mate identifica-se secularmente com a microrregião de Canoinhas. Em determinado momento de sua história, o município de Canoinhas ostentou o título de "Capital Mundial da Erva-Mate", tendo seu nome alterado para "Ouro Verde" durante parte da década de 30 do século 20 . Além de constituir um bem agrário material, a erva-mate possui um componente imaterial, que se vincula ao seu uso e ao seu processo de produção. Desde épocas imemoriais, quando apenas populações indígenas habitavam o território, a erva-mate tem sido produzida e consumida sistematicamente. Seu processo de produção possui aspectos singulares, historicamente transmitidos de geração a geração. Estes motivos caracterizam a erva-mate como patrimônio agrário, que gera identidade cultural e possui representatividade em todo o território, indicando a necessidade de seu reconhecimento e valorização, algo que poderá ser obtido por meio do processo de patrimonialização.

Acerca do pixirum, representante de patrimônio agrário imaterial, relaciona-se às práticas historicamente desenvolvidas tendo por base o trabalho familiar ou coletivo não remunerado. Exemplarmente, pode-se citar uma referência encontrada em processo judicial tramitado no início do século 20, no qual se lê a seguinte descrição: "Todos os trabalhos são executados pelo próprio posseiro e seus vizinhos, que se auxiliam reciprocamente, trabalhando de parceria" (APESC, 1910, p. 86). Em decorrência do trabalho agrário coletivo não remunerado, edificava-se uma noção de unidade entre os membros da comunidade que o praticavam, estimulando a construção e a manutenção de 
sua identidade territorial. Na microrregião de Canoinhas, o mutirão é denominado de pixirum. Essa prática agrária tradicional permite que tarefas árduas e morosas, difíceis de serem realizadas individualmente, possam ser executadas em poucos dias ou horas, como a construção de galpões, cercas, roçadas, limpeza de terrenos, colheitas e abate de animais.

Nas sociedades em que prevalece o auxílio mútuo, a colaboração contínua, a cooperação e as relações de trabalho são regidas por um contrato moral, consubstanciando os resultados positivos da rede de cooperação, pois confiar e usufruir das vantagens de confiar agrega mais confiança. Confiar, nesse contexto, tem por significado "a expectativa de reciprocidade que pessoas de uma comunidade, baseada em normas partilhadas, têm acerca do comportamento dos outros. Quem sente e sabe que pode confiar, recebe mais colaboração" (D’ARAÚJO, 2003, p. 33).

No caso do pixirum, convocar e ser convocado significa ter legitimidade perante aquela comunidade, e o fator primordial consiste no princípio da obrigação mútua, ou seja, aquele vizinho que fora beneficiado pelo trabalho dos membros do grupo deve retribuir a ajuda, atendendo imediatamente ao chamado quando convocado.

Dentre os elementos fundamentais que caracterizam o pixirum, encontra-se a obrigação intrínseca de fornecer a alimentação, tanto como necessidade para a continuidade dos trabalhos por períodos mais longos quanto como aspecto do comportamento do camponês. Ou seja, em retribuição à ajuda na roça, o beneficiário "só dá o almoço, a cachaça e faz o baile de noite" (Entrevista, Bueno, 2012). Enquanto os homens dedicam-se ao roçado, à carpida ou à colheita, as mulheres, coordenadas pela esposa do beneficiário, preparam a refeição. Normalmente carne assada e feijão são os ingredientes principais servidos no almoço (Entrevista, Rocha, 2012).

Ao final do longo e extenuante dia de trabalho, é chegada a hora mais aguardada por todos os presentes: o baile de pixirum. Essa celebração festiva, que demarca o encerramento dos trabalhos, congrega os trabalhadores envolvidos nas atividades do dia, suas esposas, outros parentes e vizinhos, e, inclusive, aqueles que não puderam comparecer ao trabalho.

A prática do pixirum não se vincula a um tipo específico de atividade produtiva agrária. Pode ser utilizado em praticamente todos os trabalhos realizados no campo, consistindo em relevante bem patrimonial imaterial existente na microrregião de Canoinhas, um bem de enorme valor sociocultural para a população camponesa, e, portanto, passível de patrimonialização, de acordo com o arcabouço proposto pelo conceito de Patrimônio Agrário.

\section{CONSIDERAÇÕES FINAIS}

Mediante o reconhecimento e proteção de bens utilizados pela atividade agrária, a categoria conceitual de patrimônio agrário promove a fusão das dimensões cultural e biológica, contribuindo para a proteção ambiental de determinadas zonas patrimoniais. Por conseguinte, o patrimônio agrário é um instrumento de proteção da agricultura tradicional, dos povos tradicionais, das práticas agroecológicas, minorando os efeitos nocivos causados pelas relações e práticas pautadas na lógica do capital, representadas, no meio rural, pelo agronegócio. 
Outrora, a região de Castilha-La Mancha era considerada um território inóspito, relegada ao esquecimento, percebida como um lugar de passagem. Nas últimas décadas, mediante estratégias pautadas em categorias patrimoniais, inclusive o patrimônio agrário, adquiriu visibilidade e tornou-se ponto de referência não apenas para cidadãos espanhóis, mas também para turistas estrangeiros de diferentes nacionalidades. É plausível afirmar que, em grande medida, tal transformação sucedeu-se a partir da elaboração de uma identidade territorial, amparada em elementos da monumental obra de Miguel de Cervantes, O Engenhoso Cavaleiro Dom Quixote de La Mancha, obra-prima da literatura universal e patrimônio da Humanidade (ROMERO, 2006, p. 211).

A aplicação do conceito de patrimônio agrário, além de permitir identificar, reconhecer, valorizar, preservar e difundir certos bens patrimoniais, ou seja, um procedimento prático, que integra tais bens em um conjunto passível de patrimonialização, também admite interpretações sob uma perspectiva alternativa, que acaba por expor não apenas suas potencialidades, mas, também, os limites e as consequências de sua aplicação. O objetivo do patrimônio agrário consiste em valorizar a atividade agrária, o agricultor e a agricultura tradicional, o que gera valorização do território e a promoção e proteção de práticas ambientalmente sustentáveis. Em última instância, pode ser considerado um instrumento de resistência local, que contraria a narrativa e a sujeição de todo e qualquer bem ao movimento global de mercantilização.

A busca por referenciais ao processo de patrimonialização pode se pautar em estratégias desenvolvidas anteriormente em outros territórios, que se fundamentem na identificação e valorização do seu patrimônio agrário como instrumento de desenvolvimento territorial. Exatamente este é o caso da Comunidade Autônoma de Castilla-La Mancha, na Espanha.

O conjunto de bens patrimoniais agrários, pertencente à microrregião de Canoinhas, permite vislumbrar um processo de busca por sua identificação, reconhecimento, proteção e valoração, o qual, além da importância sociocultural, pode configurar estratégia alternativa de desenvolvimento para o referido território. A viabilização desta estratégia dependerá de um processo constituído pelas seguintes etapas: (i) elaboração de um levantamento completo dos bens agrários presentes na microrregião de Canoinhas, suscetíveis de patrimonialiazação, sob a perspectiva do patrimônio agrário, contudo considerando também outras categorias; (ii) adoção de uma legislação patrimonial compartilhada pelos 12 municípios que compõem o território sob análise; (iii) mobilização dos atores sociais e políticos: as universidades da região, as associações civis, os poderes públicos municipais, etc.; (iv) promoção de conferências e audiências públicas, a partir das quais a população poderá atuar diretamente sobre o processo de patrimonialização, estimulando a ampliação do debate e o reconhecimento - ainda que informal - do patrimônio territorial, fortalecendo a identidade territorial e fomentando estratégias de desenvolvimento.

\section{REFERÊNCIAS}

BERNÁRDEZ GÓMESZ, M. J.; GUISADO DI MONTI, J. C. "La "Mina Espejo". Um Proyecto de Musealuzación y Visitabilidad de las Minas romanas de "Lapis Spetacularis" de Cuenca" em Actuaciones sobre el patrimônio minero-metalúrgico. SESIÓN CIENTíFICA, 3., Sociedad Española para la Defesa del Patrimonio Gelógico y Minero. Huelva: Servicio de Publicaciones de la Universidad de Huelva, 2000.

BLASQUEZ, J. M. Ciclos y temas de Ia historia de Espana. Madrid: Istmo, 1975. 
D’ARAÚJO, M. C. Capital social. Rio de Janeiro: Jorge Zahar, 2003.

DALLABRIDA, V. R. Desenvolvimento regional: por que algumas regiões se desenvolvem e outras não? Santa Cruz do Sul: Edunisc, 2015.

ENTREVISTAS: Gregório Rocha, 84 anos. Taquarizal, Canoinhas-SC; Miguel Cardoso, 50 anos. Pedras Brancas, Canoinhas-SC; Juca Bueno, 80 anos. Rio D’Areia do Meio, Canoinhas-SC.

GERHARDT, M. História ambiental da erva-mate. 2013. Tese (Doutorado em História) - Universidade Federal de Santa Catarina; Centro de Filosofia e Ciências Humanas, Florianópolis, 2013.

IBGE. Instituto Brasileiro de Geografia e Estatística, 2006/2010/2014.

INE. Instituto Nacional de Estadistica da Espanha, 2016.

LÓPEZ, J. A. C. La transición democrática en Castilla-La Mancha (1976-1983). Proceso autonómico y construcción regional. Colección Tesis, n. 5, 2007.

PILLET, F. “El turismo de interior y el patrimonio territorial en Castilla-La Mancha”. Cuadernos de Turismo, n. 27, p. 725-741, 2011.

PLAN Estratégico de Turismo 2015-2019. Castilla-La Mancha. Visión y Objetivos Estratégicos. Desarrollo de Planes y Líneas de Actuación. Disponível em: http://www.turismocastillalamancha.es/PLAN-ESTRATEGICO-TURISMO-2015-2019.pdf.

PLAZA, J. J.; CAÑIZARES, M. C.; RUIZ PULPÓN, A. R. Patrimonio, vinedo y turismo: recursos específicos para la innovación y el desarrollo territorial de La Mancha, 2017.

APESC. Arquivo Público do Estado de Santa Catarina. Processo de terra. Moças, Canoinhas, SC: Southern Brazil Lumber \& Colonization Company, 1910. (Gaveta 688. fl. 86).

MATOS, L. A. C. Itinerário desde os confins setentrionais da Capitania do Rio Grande do Sul até a cidade de São Paulo, 1797. In: Revista do Instituto Histórico Geográfico Brasileiro, 1858.

ROMERO, M. L. C. "La explotación de la figura literaria del Quijote como recurso turístico: la ruta de Don Quijote". In: CAPDEPÓN, F. P.; TABASCO, J. P. El espacio geográfico del Quijote en Castilla-La Mancha. Cuenca: Ediciones de UCLM, 2006.

RUIZ PULPÓN, A. R. "Producción agroalimentaria de calidad y postproductivismo agrario: el caso de los vinos de pago en Castilla-La Mancha". Anales de Geografía de la Universidad Complutense, v. 33, n. 2, p. 137-154, 2013.

RUIZ, J. C. (dir.). Carta de Baeza sobre patrimonio agrario. Sevilla: Universidad Internacional de Andalucía, 2013. Disponível em: http://dspace.unia.es/bitstream/handle/10334/3428/2013\%20cartabaeza.pdf.

RUIZ, J. C.; YANEZ, C. M. (coord.). El Patrimonio Agrario: la construcción cultural del territorio a través de la actividad agraria. Sevilla: Universidad Internacional de Andalucia, 2015.

SÁEZ, J. A. O. L.; SÁNCHEZ, F. A.; COLINO, T. N.; GONZÁLEZ, F. M.; DÍAZ, S. P.; RUIZ, S. S. "Paleoambiente y sociedade en la Edad del Bonce de La Mancha: La Motilla del Azuer". CPAG 24, p. 391-422, 2014.

SANTA CATARINA. Secretaria de Estado de Coordenação Geral e Planejamento - Seplan. Subsecretaria de Estudos Geográficos e Estatísticos. Atlas Escolar de Santa Catarina. Florianópolis; Rio de Janeiro: Aerofoto Cruzeiro, 1991.

SCHÄFFER, W. B.; PROCHNOW, M. A Mata Atlântica e você: como preservar, recuperar e se beneficiar da mais ameaçada floresta brasileira. Brasília: Apremavi, 2002.

SEGRELLES, J. A. "Problemas ambientales, agricultura y globalización en América Latina". In: Scripta Nova. Revista Electrónica de Ciencias Sociales y Geografía, Universidad de Barcelona, v. XVIII, n. 92, 10 jul. 2001. Disponível em: http://www.ub.edu/geocrit/sn-92.htm.

SEN, A K. Desenvolvimento como liberdade. São Paulo: Companhia das Letras, 2000.

SILVEIRA, M. C. B. A Espanha romana: conquista, colonização e desagregação. Biblos, Rio Grande, 13, p. 13-31, 2001.

TABASCO, J. P.; SANCHEZ-MATEOS, H. S. M.; REY, R. U. G. “La ordenación del territorio en Castilla-La Mancha: estado de la cuestión y estudio de casos". Cuadernos Geograficos, 47, p. 493-522, 2010-2.

TOMPOROSKI, A. A.; MARCHESAN, J. Planalto norte catarinense: algumas considerações sobre aspectos históricos, características físico-naturais e extrativismo. Desenvolvimento Regional em Debate, v. 6, p. 5163, 2016. 